\title{
PEMBUATAN PURWARUPA ALAT PENGATUR OTOMATIS PADA TANGKI AIR MENGGUNAKAN SENSOR ULTRASONIK HC - SR04 BERBASIS PLC SR3B101BD
}

\author{
Budi Santosa ${ }^{1}$, Hariyadi ${ }^{2}$ \\ Program Studi Teknik Elektro, Universitas Muhammadiyah Sumatera Barat ${ }^{1,2}$ \\ budisantosa@umsb.ac.id ${ }^{1}$, hariefamily@yahoo.co.id ${ }^{2}$ \\ DOI: http://dx.doi.org/10.31869/rtj.v2i2.1379
}

\begin{abstract}
Abstraks: Pada saat jaman sekarang pada abad terkini, hampir semua sistem tidak lagi dikendalikan secara manual, melainkan secara otomatis. Penggunaan tenaga manusia dipermudah dengan peralatan yang menunjang hampir seluruh aspek pekerjaan, dan pada jurnal ini akan dibahas bagaimana membuat sistem kontrol level cairan secara otomatis. Yang akan memberikan manfaat untuk kemudahan dalam melakukan pekerjaan. Seperti pada industri, hotel dan fasilitas publik lainya, yang membutuhkan ketersediaan air secara terus menerus untuk melayani pelanggan. serta dapat digunakan untuk memperluas wawasan bagaimana sebuah sistem yang bekerja secara waktu sebenarnya

Kata Kunci : kinerja alat, sistem, otomatis, kontrol.
\end{abstract}

\begin{abstract}
: in the present time in the current century, almost all systems are no longer manually controlled, but automatically. The use of human labor is facilitated by tools that support almost all aspects of the work, and in this jurnal will be discussed how to create a liquid level control system automatically. Which will provide benefits for ease of doing the job. As in industry, hotels and other public facilities, which require continuous water availability to serve customers. And can be used to broaden the horizons of how a system works in real time
\end{abstract}

Keywords : tool peformance, system, automatic, control

\section{PENDAHULUAN}

Dalam sebuah industri, perhotelan dan berbagai fasilitas publik penggunaan tangki banyak digunakan untuk memenuhi kebutuhan proses produksi. Tangki tidak hanya digunakan sebagai media penyimpanan tetapi juga digunakan untuk menjaga kelancaran ketersediaan cairan yang diperlukan selama proses produksi berlangsung.

Pentingnya penggunaan tangki tersebut mengharuskan tangki berada pada ketinggian normal agar proses produksi tidak terganggu. Hal tersebut menimbulkan permasalahan yaitu pekerja harus memonitor ketinggian air secara terus menerus, tentu saja dalam proses monitoring yang dilakukan berulangkali menghabiskan banyak waktu dan membutuhkan tenaga ekstra pekerja. Untuk mengatasi permasalahan tersebut, dibutuhkan sebuah teknologi pengendali jarak jauh yang dapat memudahkan pekerja dalam proses monitoring secara real time

Seiring dengan berjalannya waktu, teknologi yang merupakan buah dari ilmu pengetahuan semakin berkembang pesat. Di dalam dunia industri, perhotelan dan fasilitas publik, teknologi sangat besar pengaruhnya, terutama pada bidang otomasi

Otomasi sangat diminati karena dapat menjamin kualitas produk yang dihasilkan, memperpendek waktu produksi, dan mengurangi biaya untuk tenaga kerja manusia

Dari permasalahan yang muncul tersebut maka munculah ide penulis untuk memonitor tingkat cairan ( liquid level ) pada tangki secara otomatis, dalam sistem kontrol level cairan (liquid level control ) ini dapat menjamin kontinuitas persediaan air dalam sebuah tanki yang digunakan pada industri, perhotalan dan fasilitas publik lainnya. Dengan dukungan Programmable Logic Control ( PLC ) proses monitoring dan pengendalian sistem akan sangat dimudahkan, karena dalam prosesnya sistem bekerja melakukan pengambilan data secara sebenarnya ( real time ) untuk digunakan kembali pada proses berikutnya secara kontinu, dan dengan tampilan di layar ( display ) yang akan memudahkan untuk mengetahui hasil data dari level air yang berada pada tanki.

Rumusan masalah yang dapat dirumuskan dari permasalahan diatas adalah bagaimana menciptakan sebuah sistem kontrol level cairan ( Liquid Level Control )Otomatis yang dapat memudahkan pekerja dalam poses

\begin{tabular}{llc}
\hline ISSN 2599-2081 & Fakultas Teknik UMSB & 193
\end{tabular}


monitoring data pengendalian sistem secara sebenarnya ( real time )serta dapat mengurangi kemungkinan terjadinya kesalahan pekerja ( human error )

Tujuan dan kontribusi penelitian ini adalah

a. Memaparkan kinerja PLC sebagai pengendali sistem kerja peralatan

b. Memaparkan keefektifan dan keefesienan pemanfaatan sistem automatis on/off pada mesin pompa air menggunakan indikator lamp buzzer dan sensor ultrasonik

\section{DASAR TEORI}

Sistem kontrol telah menunjukkan peranan yang sangat penting dalam berbagai kehidupan manusia. Perkembangannya meluas dari yang pada awalnya hanya berupa kontrol manual kini beberapa diantaranya telah dapat digantikan oleh kontrol otomatis ( otomasi ). Istilah otomasi ini digunakan untuk mendeskripsikan operasi atau kontrol otomatis dari sebuah proses.

Dalam zaman sekarang, semua serba praktis dan modern, penggunaan sistem otomasi terus menerus mengalami peningkatan. Ada kalanya proses kini tidak memerlukan tenaga manusia sehingga kontrol otomasi terhadap mesin menjadi bahagian yang vital. Keuntungan dari kontrol semacam ini mencakup konsistensi produk yang lebih baik, berkurangnya biaya produksi dan tingkat keamanan dan tingkat keselamatan yang lebih tinggi.

Secara sederhana, sistem kontrol merupakan usaha atau perlakuan terhadap suatu sistem dengan masukan tertentu guna mendapatkan keluaran sesuai dengan yang diinginkan. Selain itu, sistem kontrol dapat didefenisikan pula sebagai hubungan timbal balik antara elemen - elemen yang membentuk suatu konfigurasi sistem yang memberikkan suatu hasil berupa respon yang dikehendaki

Sistem liquid level control menggunakan PLC ini diidukung oleh arduino, sensor ultrasonik HC-SR04 dan lampu pilot sebagai indikatornya, pada sistem ini pompa air akan dibuat bekerja otomatis sesuai dengan perintah yang diterima melalui PLC.

\section{Metode Penelitian}

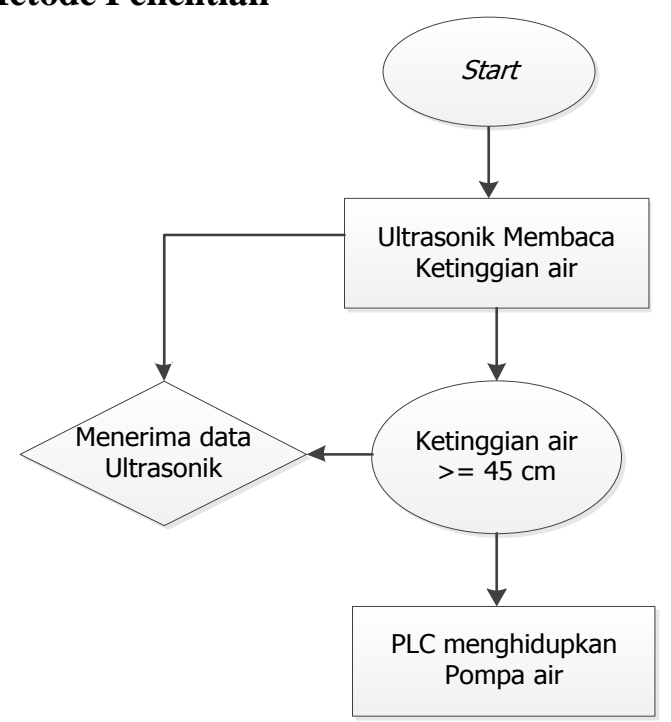

Gambar 1. Kondisi Pompa Hidup

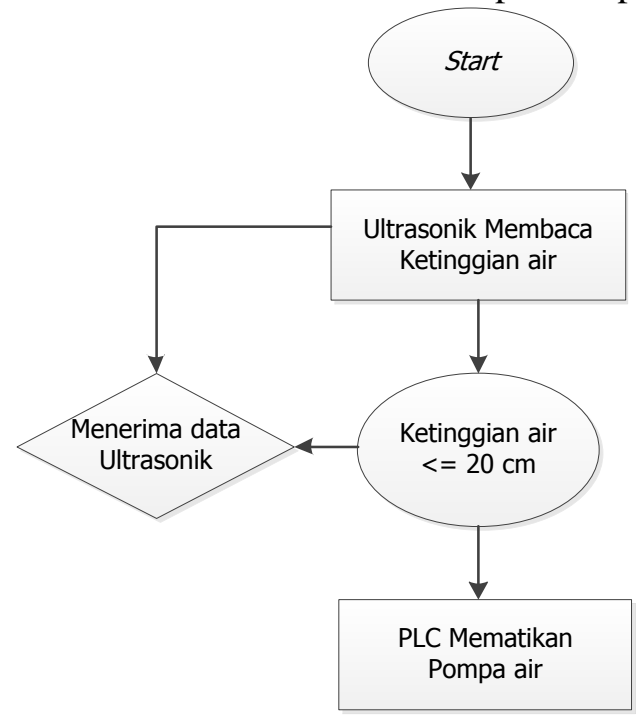

Gambar 2. Kondisi Pompa Mati

Di atas tangki air terdapat sensor ultrasonik yang berfungsi untuk mengukur jarak ketinggian air yang berada dalam tangki, cara kerjanya cukup mudah dimana sensor akan menembakan sinyal ke arah air yang berada dalam tangki, dan air akan memantulkan kembali sinyal tersebut. Sinyal yang diterima oleh sensor ultrasonik akan diteruskan ke arduino, dimana arduino yang telah diprogram akan menentukan ketinggian level air berdasarkan tegangan yang diterima dari sensor, arduino berfungsi untuk menaikan tegangan untuk di supply ke PLC, dengan menggunakan teknik analog, arduino berfungsi untuk menentukan mana pin yang akan diberi sinyal HIGH atau LOW, PLC sendiri berfungsi untuk menentukan apakah mesin akan dihidupkan atau dimatikan secara otomatis 
sesuai ketinggian air yang berada dalam tangki dan tegangan yang dikirimkan dari pin arduino. Penentuan ini pun didasarkan dari tegangan yang diterima dari arduino, prinsip kerjanya seperti gerbang OR, dimana jika salah satu pin bernilai 1 dan pin lain bernilai 0 atau sebaliknya, maka PLC akan bekerja sesuai program yang telah dirancang

Tabel 1. Alat yang digunakan dalam pembuatan system

\begin{tabular}{|l|l|l|}
\hline NO & NAMA ALAT & JUMLAH \\
\hline 1 & Multitester & 1 \\
\hline 2 & Potensio 1K, 10k, 50k & 5 \\
\hline 3 & Voltmeter Digital & 1 \\
\hline 4 & Amperemeter digital & 1 \\
\hline 5 & Obeng ( + ) dan ( - ) & 1 \\
\hline 6 & Gergaji & 1 \\
\hline 7 & Gunting & 1 \\
\hline 8 & Solder & 1 \\
\hline 9 & Spidol & 1 \\
\hline 10 & Amplas & Secukupnya \\
\hline 11 & Glue Gun & 1 \\
\hline
\end{tabular}

Tabel 2. Bahan yang digunakan

\begin{tabular}{|c|l|c|c|}
\hline NO & \multicolumn{1}{|c|}{ NAMA BAHAN } & JUMLAH & SATUAN \\
\hline 1 & $\begin{array}{l}\text { PLC Schanider Electric Zelio SR3 } \\
\text { B101BD }\end{array}$ & 1 & Unit \\
\hline 2 & Sensor Ultrasonik HC - SR04 & 1 & Unit \\
\hline 3 & Arduino UNO & 1 & Unit \\
\hline 4 & LCD LMB162AFC 2x16 & 1 & Unit \\
\hline 5 & LED MERAH & 4 & Buah \\
\hline 6 & SKUN Y & 25 & Buah \\
\hline 7 & Power Supply 24 Volt S-150-24 & 1 & Unit \\
\hline 8 & Relay ZN MYN 24 Volt & 30 & Buah \\
\hline 9 & Relay XHONG 24 VDC & 5 & Buah \\
\hline 10 & TIP 41 & 5 & Buah \\
\hline 11 & TIP 42 & 1 & Buah \\
\hline 12 & IC 7809F & 1 & Meter \\
\hline 13 & Kabel Visicom 2 x 0,75 mm ${ }^{2}$ & 5 & Meter \\
\hline 14 & Kabel kabel metal 2.5 mm m $^{2}$ & 1 & Unit \\
\hline 15 & MH Real Time Clock Module & 20 & Buah \\
\hline 16 & Fuse & 3 & Meter \\
\hline 17 & Kabel Jumper & 1 & Unit \\
\hline 18 & Selang & 12 & Buah \\
\hline 19 & Pompa air & 4 & Buah \\
\hline 20 & Resistor & & \\
\hline 21 & LED BIRU & & 5 \\
\hline
\end{tabular}


Gambar 3. Gambar 3 Blok diagram Sistem

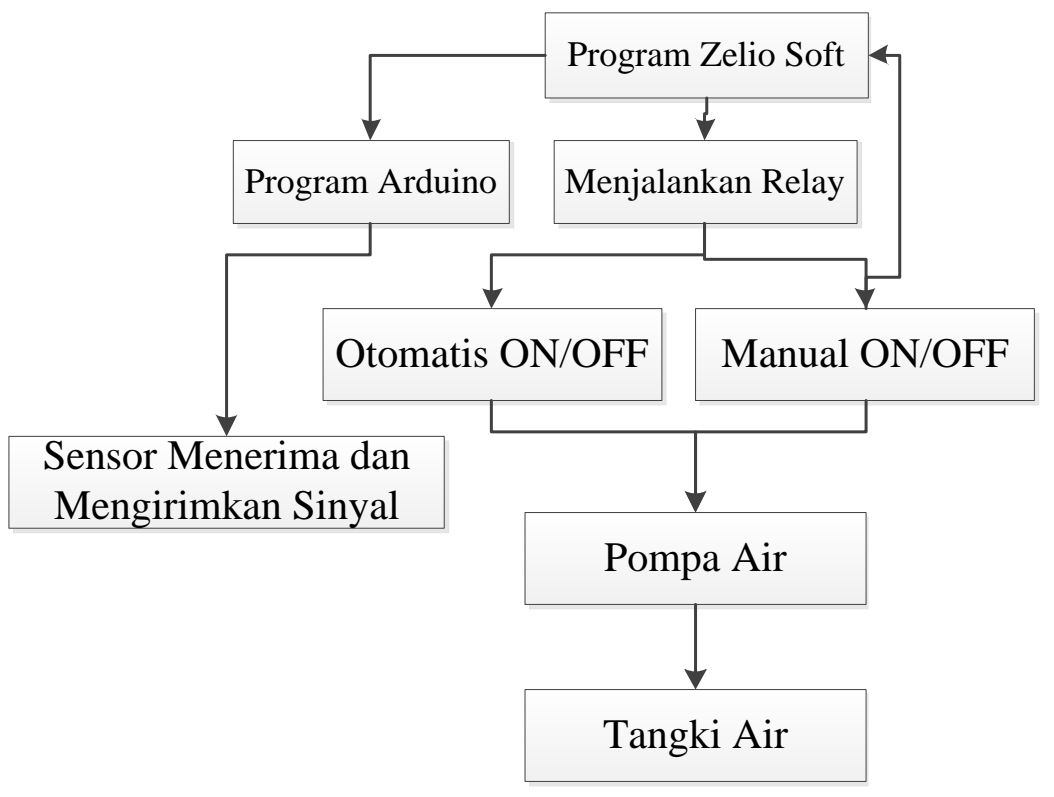

\section{HASIL DAN PEMBAHASAN}

Hasil

Meliputi perangkat lunak ( software) dan perangkat keras ( hardware), gabungan kedua perangkat inilah yang membentuk sebuah sistem liquid level control otomatis Tabel 3. Hasil Pembacaan Sensor

\begin{tabular}{|l|l|l|}
\hline No & $\begin{array}{l}\text { Level Air } \\
(\text { liter })\end{array}$ & $\begin{array}{l}\text { jarak sensor } \\
(\mathrm{cm})\end{array}$ \\
\hline 1 & 2 & 43 \\
\hline 2 & 3 & 41 \\
\hline 3 & 4 & 39 \\
\hline 4 & 5 & 37 \\
\hline 5 & 6 & 35 \\
\hline 6 & 7 & 33 \\
\hline 7 & 8 & 31 \\
\hline
\end{tabular}

\begin{tabular}{|l|l|l|}
8 & 9 & 30 \\
\hline 9 & 10 & 28 \\
\hline 10 & 11 & 26 \\
\hline 11 & 12 & 24 \\
\hline 12 & 13 & 22 \\
\hline 13 & 14 & 20 \\
\hline 14 & 15 & 18 \\
\hline 15 & 16 & 16 \\
\hline
\end{tabular}

variabel terikat yang dipengaruhi oleh variabel bebas yaitu variasi ketinggian cairan di dalam tangki. Dengan mengatur nilai variabel pada program PLC, maka sistem akan dapat bekerja secara otomatis. 


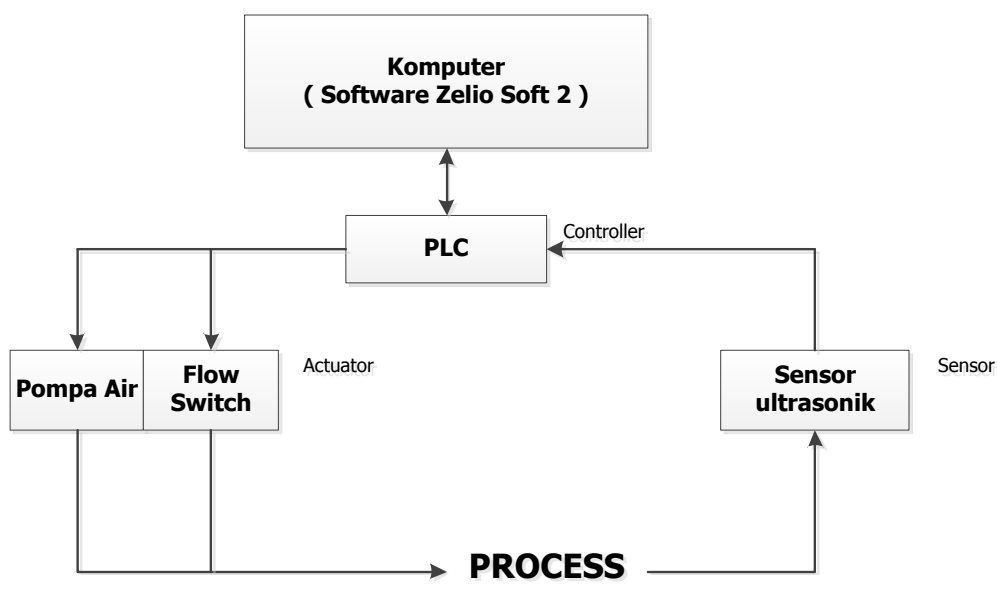

Gambar 4. Alur Kerja Kontrol Level Cairan

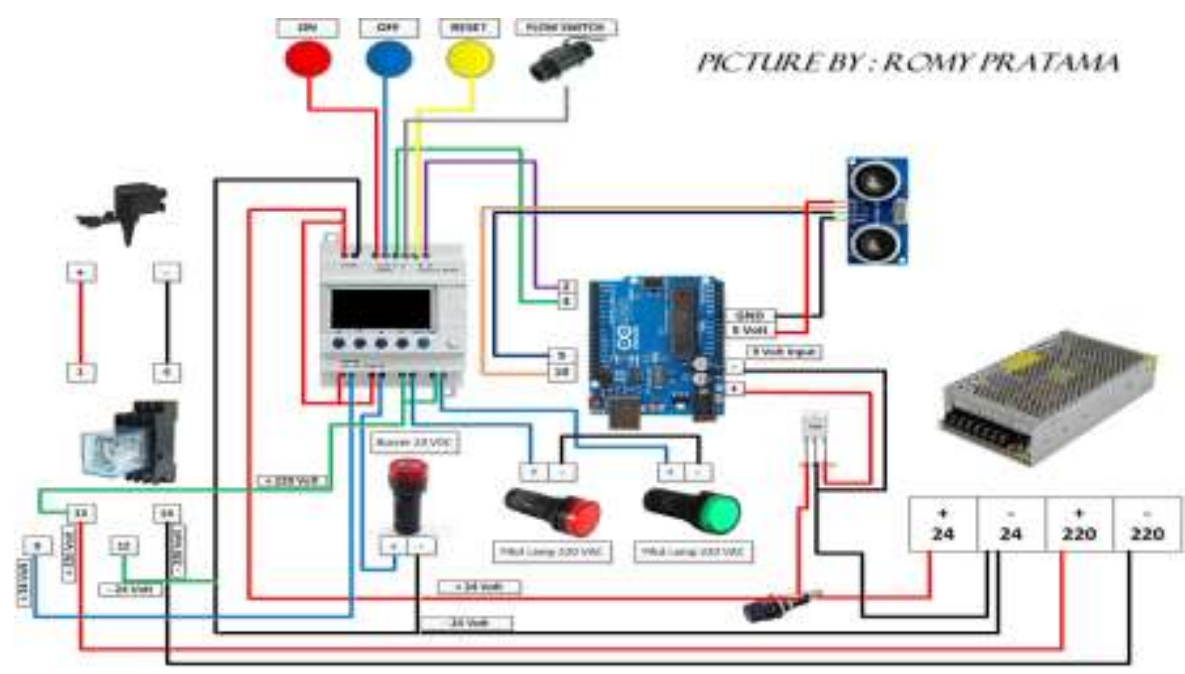

Gambar 5. Rangkaian Keseluruhan Alat

\section{Pembahasan}

Meliputi pembahasan program PLC yang digunakan

Pada anak tangga 1

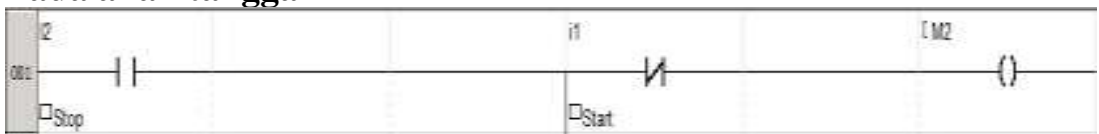

Gambar 6. Ladder 1

Pada anak tangga 2

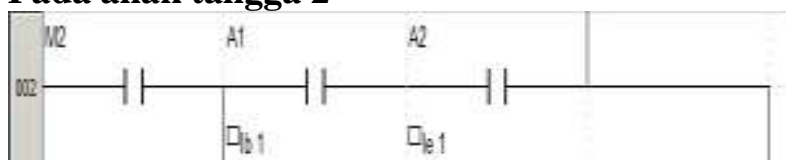

Gambar 7. Ladder 2

pada anak tangga 3

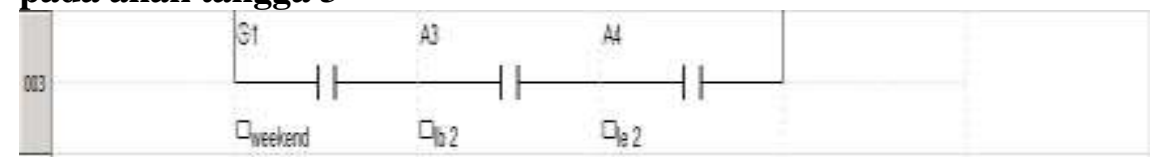

Gambar 8. Ladder 3

pada anak tangga 4 
Vol. 2 No.2 Juni 2019

http://jurnal.umsb.ac.id/index.php/RANGTEKNIKJOURNAL

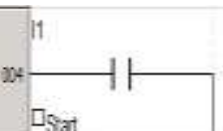

Gambar 9. Ladder 4

pada anak tangga 5

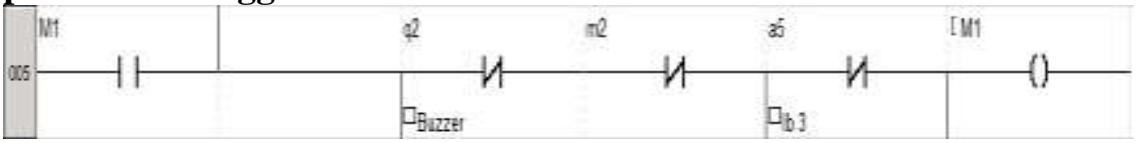

Gambar 10. Ladder 5

Pada anak tangga 6
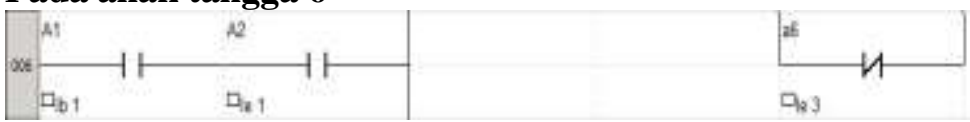

Gambar 11. Ladder 6

Pada anak tangga 7

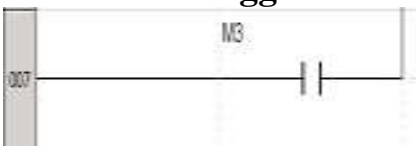

Gambar 12. Ladder 7

Pada anak tangga 8

$\square_{\text {wexand }}$

Gambar 13. Ladder 8

Pada anak tangga 9

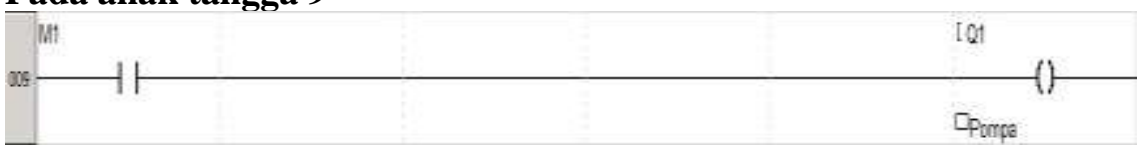

Gambar 14. Ladder 9

Pada anak tangga 10

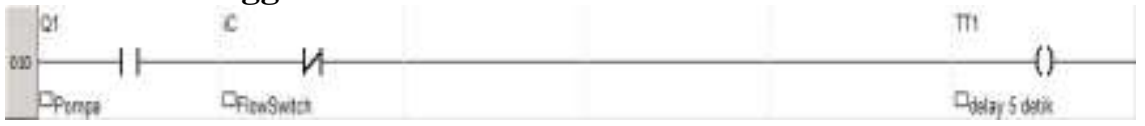

Gambar 15. Ladder 10

Pada anak tangga 11

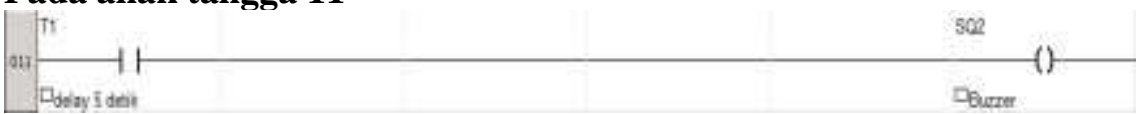

Gambar 16. Ladder 11

Pada anak tangga 12

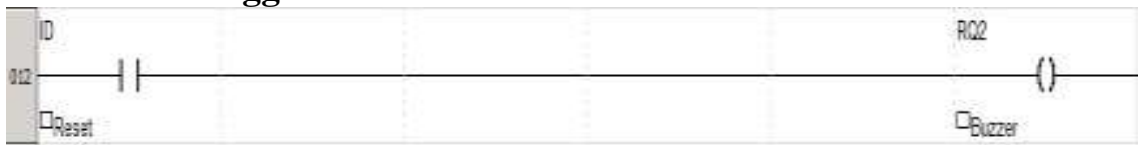

Gambar 17. Ladder 12

Pada anak tangga 13

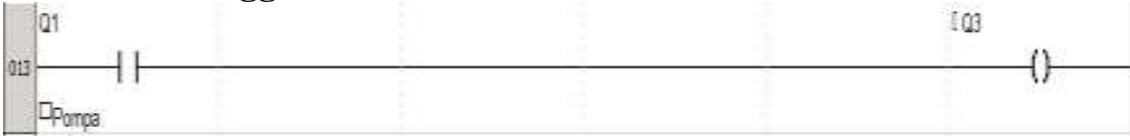

Gambar 18. Ladder 23

Pada anak tangga 14

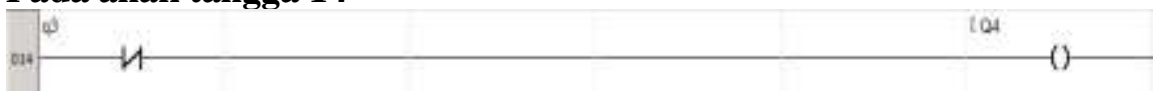

Gambar 19. Ladder 24

$\begin{array}{lr}\text { Fakultas Teknik UMSB } & \text { ISSN 2599-2081 } \\ \text { EISSN 2599-2090 }\end{array}$


Tangga 1 : Jika kontak 1 i2 mendapat arus maka i2 yang status normal adalah normally open akan menjadi normally close

Tangga $2: \mathrm{m} 2$ disini difungsikan sebagai coil pengganti output PLC, dimana pada anak tangga 2 ini digunakan untuk mengunci kinerja dari i2 pada anak tangga pertama. A1 dan A2 disini yang berlabel ib1 dan ie1 merupakan input masukan analog dari sinyal diskrit yang diterima dari sensor ultrasonik melalui arduino.

Tangga 3 : fungsinya sama pada anak tangga 2 , walaupun pompa hidup dengan kondisi air berada pada level bawah, dengan menekan tombol stop maka sistem dapat dimatikan secara paksa, dan akan memulai kembali saat tombol start ditekan

Tangga 4 : ketika arus dialiri ke i1 yang berfungsi sebagai tombol start maka akan di lanjutkan pada anak tangga selanjutnya

Tangga 5 : $\mathrm{m} 1$ pada kontak 1 berfungsi untuk menahan arus agar dapat terus mengaliri sistem,. q2 berfungsi sebagai buzzer, $\mathrm{m} 2$ berfungsi sama yang digunakan untuk mematikan sistem secara paksa, baik dalam kondisi hidup dan bekerja. Di kontak 5 terdapat a5 dan a6 yang berfungsi sebagi patokan maksimal ketinggian air, ketika air telah mencapai $100 \%$ atau tegangan yang diterima PLC dan arduino mencapai 4 volt, atau masingmasing dari input ib dan ie menerima tegangan lebih atau besar dari 4 volt, a5 dan 6 akan bekerja untuk mengeksekusi perintah agar mematikan pompa.

Tangga 6 : Jika tegangan diterima oleh A1 ( ib 1 ) >= 4 volt, dan tegangan yang diberikan arduino ke input A2 ( ie 1 ) $<=1$ volt, maka pompa akan otomatis hidup dan akan bekerja sampai air penuh.

Tangga 7 : M3 disini berfungsi dari ladder selanjutnya, dimana akan bekerja sesuaian dengan perintah yang diberikan untuk mengaktikan M3

Tangga 8 : Terdapat clock 1 ( weekend) dimana PLC akan bekerja dengan settingan yang berbeda dengan hari biasanya, jika arus pada A4 ( ie 2 ) mendapat tegangan $>=4$ volt, dan A3 mendapat tegangan $<=1$ volt, maka pompa akan hidup saat kondisi $50 \%$

Tangga 9 : Jika M1 mendapatkan arus dari perintah start manual, ataupun otomatis dari iB maka m1 akan menutup menjadi normally close
Tangga 10 : Jika Q1 dalam kondiri on maka iC yang disini ialah sebagai flow switch akan menghitung TT1 delay selama 5 detik

Tangga 11 : Jika delay T1 telah mencapai 5 detik maka T1 akan memerintahkan koil, koil disini adalah SQ2, agar berfungsi dan menghidupkan buzzer

Tangga 12 : iD disini berfungsi sebagai reset dimana akan bekerja pada RQ2 atau berguna untuk mengembalikan buzzer dan sistem pada kondisi awal.

Tangga 13 : Jika Q1 ( pompa ) dalam keadaan hidup , maka Q3 akan bekerja, dimana Q3 adalah lampu indikator

Tangga 14 : Jika Q1 ( pompa) dalam keadaan mati, maka Q4 akan bekerja, dimana Q3 adalah lampu indikator yang menandakan bahwa pompa dalam kondisi off

\section{PENUTUP}

\section{Simpulan}

Sistem liquid level control otomatis yang telah dibuat, dapat melakukan kontrol secara otomatis maupun manual dan bekerja secara real time dengan baik, sehingga sistem ini dapat memudahkan pekerja dalam pekerjaannya

Saran

Untuk sistem liquid level control penempatan sensor ultrasonik, ditempatkan pada posisi yang benar agar hasil pembacaan lebih stabil

\section{DAFTAR RUJUKAN}

Banzi, Massimo. 2008. "How Arduino is OpenSourcing imagination". England, O'Reilly.

Abdul, Kadir. 2013. "Panduan praktis mempelajari aplikasi mikrokonroler dan pemograman menggunakan arduino". Yogyakarta, Andi.

Monice, Monice. "Analisis Pemanfaatan Energi dari Pengolahan Metode Landfiil di TPA Muara Fajar Pekanbaru." Rang Teknik Journal 1.2 (2018).

Santosa, B., \& Hariyadi, Y. (2018). PEMBUATAN ALAT LABORATORIUM TEKNIK DIGITAL DASAR UNTUK IMPLEMENTASI MATAKULIAH TEKNIK DIGITAL PADA PROGRAM STUDI TEKNIK ELEKTRO UNIVERSITAS 
MUHAMMADIYAH SUMATERA

BARAT. Menara Ilmu, 12(11)

Schneider, electric. " SR3B101BD" diambil

dari: http://www.schneider-

electric.com/en/search/SR3b101bd 